\title{
Histone Acetylation of Immune Regulatory Genes in Human Placenta in Association with Maternal Intake of Olive Oil and Fish Consumption
}

\author{
Nathalie Acevedo ${ }^{1,2}{ }^{\oplus}$, Paolo Frumento ${ }^{3}$, Hani Harb ${ }^{4,5}{ }^{\oplus}$, Bilal Alashkar Alhamwe ${ }^{4,6}(\mathbb{D}$, \\ Catharina Johansson ${ }^{1}\left(\mathbb{D}\right.$, Lisa Eick ${ }^{4}$, Johan Alm ${ }^{1} @$, Harald Renz ${ }^{4}\left(\mathbb{D}\right.$, Annika Scheynius ${ }^{1,7,+}$ \\ and Daniel P. Potaczek ${ }^{4,8, *, \dagger}$ \\ 1 Department of Clinical Science and Education, Karolinska Institutet, and Sachs' Children and Youth \\ Hospital, Södersjukhuset, 11883 Stockholm, Sweden; nacevedoc@unicartagena.edu.co (N.A.); \\ catharina.johansson@ki.se (C.J.); johan.alm@ki.se (J.A.); annika.scheynius@ki.se (A.S.) \\ 2 Institute for Immunological Research, University of Cartagena, Cartagena 130015, Colombia \\ 3 Unit of Biostatistics, Institute of Environmental Medicine, Karolinska Institutet, 17177 Stockholm, Sweden; \\ paolo.frumento@ki.se \\ 4 Institute of Laboratory Medicine, member of the German Center for Lung Research (DZL), \\ Universities of Giessen and Marburg Lung Center (UGMLC), and the inVIVO Planetary Health, \\ Group of the Worldwide Universities Network (WUN), Philipps-University Marburg, 35043 Marburg, \\ Germany; hani.harb@childrens.harvard.edu (H.H.); alashkab@staff.uni-marburg.de (B.A.A.); \\ lisaeick@t-online.de (L.E.); harald.renz@uk-gm.de (H.R.) \\ 5 Division of Immunology, Boston Children's Hospital, Harvard Medical School, Boston, MA 02115, USA \\ 6 College of Pharmacy, International University for Science and Technology (IUST), Daraa 15, Syria \\ 7 Clinical Genomics, Science for Life Laboratory, 17165 Stockholm, Sweden \\ 8 John Paul II Hospital, 31-202 Krakow, Poland \\ * Correspondence: potaczek@staff.uni-marburg.de \\ + Shared last authorship.
}

Received: 29 January 2019; Accepted: 26 February 2019; Published: 1 March 2019

check for updates

\begin{abstract}
Maternal diet modifies epigenetic programming in offspring, a potentially critical factor in the immune dysregulation of modern societies. We previously found that prenatal fish oil supplementation affects neonatal T-cell histone acetylation of genes implicated in adaptive immunity including PRKCZ, IL13, and TBX21. In this study, we measured H3 and H4 histone acetylation levels by chromatin immunoprecipitation in 173 term placentas collected in the prospective birth cohort, ALADDIN, in which information on lifestyle and diet is thoroughly recorded. In anthroposophic families, regular olive oil usage during pregnancy was associated with increased $\mathrm{H} 3$ acetylation at FOXP3 $(p=0.004), \operatorname{IL10RA}(p=0.008)$, and IL7R $(p=0.007)$ promoters, which remained significant after adjustment by offspring gender. Furthermore, maternal fish consumption was associated with increased $\mathrm{H} 4$ acetylation at the CD14 gene in placentas of female offspring $(p=0.009)$. In conclusion, prenatal olive oil intake can affect placental histone acetylation in immune regulatory genes, confirming previously observed pro-acetylation effects of olive oil polyphenols. The association with fish consumption may implicate $\omega-3$ polyunsaturated fatty acids present in fish oil. Altered histone acetylation in placentas from mothers who regularly include fish or olive oil in their diets could influence immune priming in the newborn.
\end{abstract}

Keywords: ALADDIN; fish; H3; H4; histone acetylation; immune genes; maternal diet; olive oil; placenta; pregnancy 


\section{Introduction}

Maternal diet can modify the epigenetic landscape in diverse tissues and is a crucial factor in the developmental programing of the offspring [1-3]. Human and mice studies support the substantial effects of maternal diet on the expression of metabolic, immune, and neurodevelopmental genes, which is mediated in part through the alteration of histone acetylation marks [4-6]. Histone acetylation is an epigenetic mechanism that consists in the addition of acetyl groups to lysines protruding in the $\mathrm{N}$-terminal tail of histones, a process mediated by histone acetyltransferases, histone deacetylases, and complex epigenetic machineries. Increased acetylation of histones $\mathrm{H} 3$ and $\mathrm{H} 4$ is typically associated with open chromatin leading to better accessibility of promoters to the transcriptional machinery and hence higher gene expression $[7,8]$.

Several compounds (i.e., sulforaphane, curcumin, polyphenol flavonoids, butyrate, indole-3-carbinol, and organosulfur compounds) have been shown to modify histone acetylation levels [9]. Recent experimental evidence highlights the role of fish oil and its bioactive component n-3 polyunsaturated fatty acids (PUFA) as significant epigenetic modifiers of histone marks [10]. The availability of n-3 PUFA during gestation modifies $\mathrm{H} 3$ acetylation in fetal neurons and astrocytes [5]. Moreover, we recently found that fish oil supplementation affects histone acetylation levels in neonatal $\mathrm{T}$ cells, affecting immune genes such as protein kinase $\mathrm{C}$ zeta gene (PRKCZ), IL13, and T-box 21 gene (TBX21) [11,12]. In addition, the gene forkhead box P3 (FOXP3), which encodes a master regulator of immune homeostasis, has shown to be epigenetically modified by dietary compounds including all-trans retinoid acid [13], microbial-derived butyrate [14], and propionate [15]. This gene is especially important because animal models suggest that FOXP3 is epigenetically modified by dietary exposures, such as high fiber and acetate, during the prenatal period [16].

Placenta constitutes a critical interface mediating the intrauterine maternal effects on epigenetic programming [17]. For instance, maternal obesity is associated with altered mRNA expression of key acetylation modifiers in placenta, including histone deacetylases and lysine acetyltransferases [18]. In rats, dietary unsaturated fatty acids in maternal diet [eicosapentaenoic acid (EPA, 20:(5n-3)) + docosahexaenoic acid (DHA, 22:(6n-3))] exhibited a profound effect in modulating the epigenetic parameters in placenta and fetal liver [19]. Previous studies in the Assessment of Lifestyle and Allergic Disease During INfancy (ALADDIN) cohort suggested that CD14, a co-receptor of toll-like receptors critical in innate immune sensing, is epigenetically modified in human placenta, but the exposures involved require better definition [20]. In the present study, we hypothesized that acetylation levels of $\mathrm{H} 3$ or $\mathrm{H} 4$ histones at the promoters of immune regulatory genes are associated with lifestyle and diet during pregnancy. We evaluated histone acetylation in 173 placentas from the prospective birth cohort ALADDIN in which extensive information on lifestyle and diet has been previously recorded [21] in anthroposophic, partly anthroposophic, and non-anthroposophic families from the Stockholm area, Sweden. The dietary patterns related with the anthroposophic lifestyle in this cohort included an increased frequency of vegetarian diet, consumption of organic/biodynamic food, use of butter on bread, and use of olive oil as main cooking fat [21].

\section{Results and Discussion}

A total of 173 placenta specimens were analyzed by chromatin immunoprecipitation (ChIP) and quantitative polymerase chain reaction (PCR) to measure both $\mathrm{H} 3$ and $\mathrm{H} 4$ pan-acetylation levels at the promoters of four candidate immune genes, which have previously shown to be epigenetically modified by early life exposures (CD14 and FOXP3) $[16,20,22]$ or epigenetically altered in T cells (IL10RA and ILR7) [Acevedo et al., Unpublished]). The ALADDIN study includes families with anthroposophic, partly anthroposophic, and non-anthroposophic lifestyles [21]. As a result of the limited number of available placenta specimens in the anthroposophic group, in this study, this group was combined with the partly anthroposophic group (A + PA). The demographic characteristics of the participating families are presented in Table 1. Maternal age at birth, parity, offspring gender, and birth weight did not differ between the two groups. 
Table 1. Demographic data of participating families.

\begin{tabular}{cccc}
\hline Characteristic & $\begin{array}{c}\text { Non-Anthroposophic } \\
(\mathbf{N}=\mathbf{4 3})\end{array}$ & $\begin{array}{c}\text { Anthroposophic + Partly } \\
\text { Anthroposophic (N=25+ 105) }\end{array}$ & $p_{\text {-Value * }}^{*}$ \\
\hline Maternal age (years) & $30(28-33)$ & $31(27-34)$ & 0.46 \\
\hline Parity & & & 0.97 \\
\hline first & $17 / 43(40 \%)$ & $53 / 128(41 \%)$ & 0.81 \\
\hline second & $18 / 43(42 \%)$ & $49 / 128(38 \%)$ & 0.98 \\
\hline third or more & $8 / 43(19 \%)$ & $26 / 128(20 \%)$ & 0.11 \\
\hline Mother vegetarian diet during pregnancy & $2 / 38(5 \%)$ & $22 / 126(17 \%)$ & 0.05 \\
\hline Mother smoking during pregnancy & $8 / 42(19 \%)$ & $9 / 127(7 \%)$ & 0.96 \\
\hline Father smoking during pregnancy & $11 / 41(27 \%)$ & $31 / 125(25 \%)$ & 0.12 \\
\hline Female offspring & $28 / 43(65 \%)$ & $65 / 130(50 \%)$ & 0.64 \\
\hline Birth weight (gram) & $3510(3312-4010)$ & $3568(3348-3939)$ & 0.01 \\
\hline Gestational age in weeks & $39(38-40)$ & $40(39-41)$ & \\
\hline
\end{tabular}

Continuous variables are presented as median (interquartile range). Categorical variables are presented as $n / N=$ yes/total number (\%). ${ }^{*}$ Chi-square test for comparing categorical variables and Mann-Whitney U test for continuous variables.

In comparison with mothers from non-anthroposophic families, mothers with A + PA lifestyle reported a more frequent use of olive oil as main cooking fat during pregnancy [55\% (22/40) vs. $78 \%(98 / 125)$, respectively; $p=0.007]$ and a more frequent consumption of butter or butter-based, full-fat margarine on bread during pregnancy [21\% (9/42) vs. $66 \%(84 / 127)$, respectively; $p<0.001]$ (Figure 1). Maternal fish consumption during pregnancy did not differ between the two lifestyle groups (Figure 1). The distribution of these variables in this dataset clearly resembles that previously described by Stenius et al. [21].

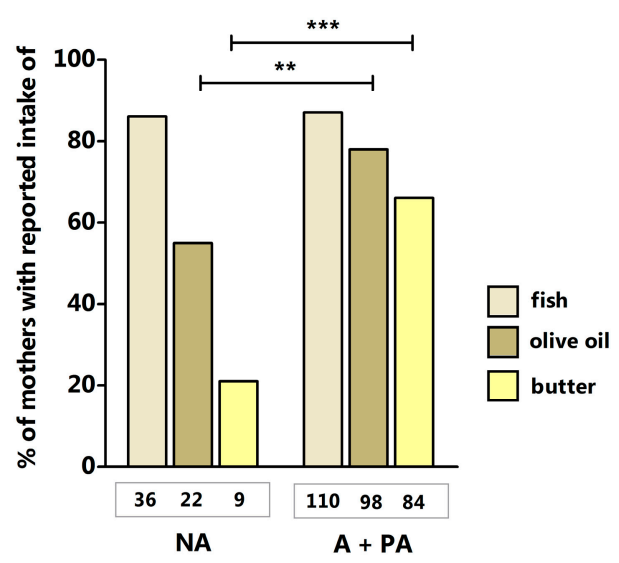

Figure 1. Prevalence of prenatal consumption of fish, olive oil, and butter in non-anthroposophic (NA), anthroposophic, or partially anthroposophic mothers (A + PA). Numbers of mothers with complete data on dietary exposures are presented below the bars. Fisher exact test: ${ }^{* *} p=0.007 ;{ }^{* * *} p<0.001$.

We found that $\mathrm{H} 3$ acetylation levels at the promoters of FOXP3, interleukin 10 receptor subunit alpha (IL10RA), and interleukin 7 receptor (IL7R) genes were significantly increased in the placenta specimens from mothers who regularly used olive oil as the main cooking fat during pregnancy. This association was detected in mothers with an A + PA lifestyle but was not observed in non-anthroposophic mothers (Figure 2). H3 acetylation levels in placentas were not associated with maternal fish consumption during pregnancy or regular intake of butter or butter-based, full-fat margarine on bread (data not shown). 
H3 acetylation - FOXP3

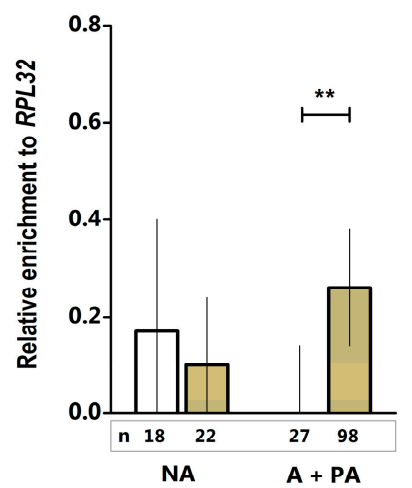

H3 acetylation - IL10RA

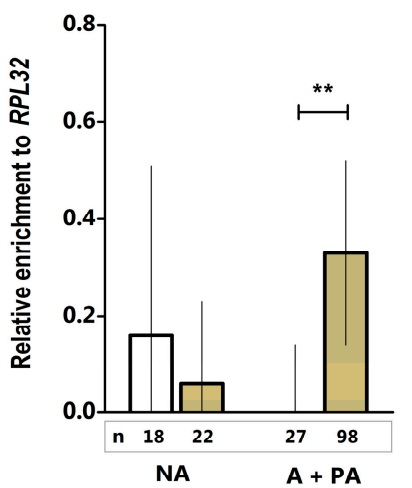

H3 acetylation - IL7R

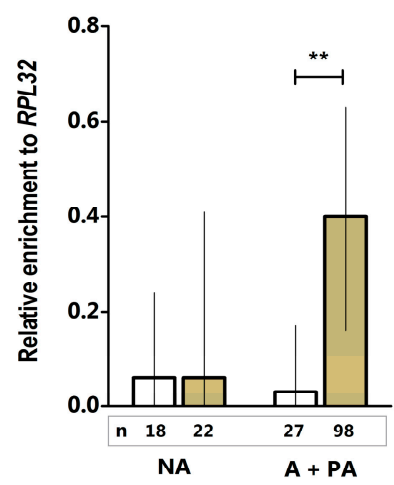

Mother used olive oil as main cooking fat during pregnancy?

Figure 2. H3 histone acetylation levels (median with 95\% confidence interval) in placenta according to the maternal use of olive oil as main cooking fat during pregnancy. NA denotes non-anthroposophic group; A, anthroposophic group; PA, partially anthroposophic group. Numbers of mothers with complete data on dietary exposures are presented below the bars. ${ }^{* *} p$ value $<0.01$.

Demographic variables that could potentially influence placenta acetylation, such as maternal age at birth, parity, birth weight gestational age, or parental smoking (Table 1), were not associated with $\mathrm{H} 3$ acetylation levels of FOXP3, IL10RA or IL7R (data not shown). We then implemented median regression adjusting by offspring gender in the group of A + PA mothers (Table 2) to further confirm the association between maternal use of olive oil as main cooking fat during pregnancy on placenta histone acetylation.

Table 2. Association between olive oil consumption and $\mathrm{H} 3$ acetylation levels in placenta in anthroposophic and partly anthroposophic families $(n=125 *)$.

\begin{tabular}{ccc}
\hline Predictor: Olive Oil (Yes) & $\boldsymbol{\beta} \mathbf{( 9 5 \% ~ C I ) , ~} \boldsymbol{p}$-Value (Crude) & $\begin{array}{c}\boldsymbol{\beta} \text { (95\% CI), } \boldsymbol{p} \text {-Value } \\
\text { (Adjusted by Offspring Gender) }\end{array}$ \\
\hline H3 FOXP3 & $0.26(0.08-0.43), p=0.004$ & $0.21(0.01-0.41), p=0.03$ \\
\hline H3 IL10RA & $0.31(0.09-0.54), p=0.008$ & $0.31(0.08-0.54), p=0.008$ \\
\hline H3 IL7R & $0.36(0.10-0.62), p=0.007$ & $0.36(0.10-0.61), p=0.006$ \\
\hline
\end{tabular}

* Families with complete data on maternal dietary use of olive oil (see Figure 2). CI denotes confidence interval.

These findings suggest that compounds in olive oil may have particularly important effects on the histone marks in placenta. Our results are in line with those showing that olive oil polyphenols (i.e., oleuropein aglycone) increase $\mathrm{H} 3$ and $\mathrm{H} 4$ histone acetylation by down regulating HDAC2 [23], and with the potential pro-acetylation effects of hydroxytyrosol (HT), a compound in Olea europaea, which can bind with high affinity to chromatin-modifying enzymes and inhibit HDAC6 and the lysine-specific histone demethylase 1 (LSD1) [24]. Because increased acetylation may lead to elevated transcriptional activities of these genes, we anticipated that a reduction in acetylation in placentas from mothers who do not include olive oil in their diets could modify the accessibility of FOXP3, IL10RA, and IL7R promoters to the transcriptional machinery and, accordingly, expression. This may affect early innate immune responses, anti-inflammatory mechanisms [25,26], generation of regulatory T-cells, and tolerance [27]. The association between olive oil intake and increased acetylation of FOXP3 is of great interest because this gene is critical for immune regulation and has been found to undergo modification by polyunsaturated fatty acids during pregnancy [16].

Moreover, maternal fish consumption during pregnancy was associated with increased $\mathrm{H} 4$ histone acetylation at the CD14 promoter in placentas of female offspring but not in males (Figure 3). 
This observation remained significant in either the crude median regression model $[\beta=0.30,95 \% \mathrm{CI}$ $(0.08-0.53), p=0.009]$ or adjusted by lifestyle $[\beta=0.25,95 \% \mathrm{CI}(0.02-0.47), p=0.03]$. The association of decreased $\mathrm{H} 4$ acetylation of CD14 with no maternal fish consumption observed in girls was driven by the group of non-anthroposophic mothers [ $\beta=0.39,95 \% \mathrm{CI}(0.2-0.58), p<0.0001]$. H4 acetylation levels in placentas were not associated with the maternal use of olive oil as the main cooking fat during pregnancy or the regular intake of butter or butter-based, full-fat margarine on bread (data not shown). Other factors such as maternal age at birth, parity, birth weight, parental smoking, and gestational age (Table 1) were not associated with $\mathrm{H} 4$ acetylation levels of CD14 (data not shown).

The relationship between maternal fish consumption and $\mathrm{H} 4$ acetylation levels in placenta could be attributed to $\omega-3$ polyunsaturated fatty acids (n-3 PUFAs) present in fish oil and is in agreement with previous studies suggesting that PUFAs can modify the epigenome [28]. Indeed, we have recently shown that prenatal fish oil supplementation affects acetylation of immune genes such as protein kinase C zeta gene (PRKCZ), IL13, and the T-box 21 gene (TBX21) [11].

H4 acetylation - CD14

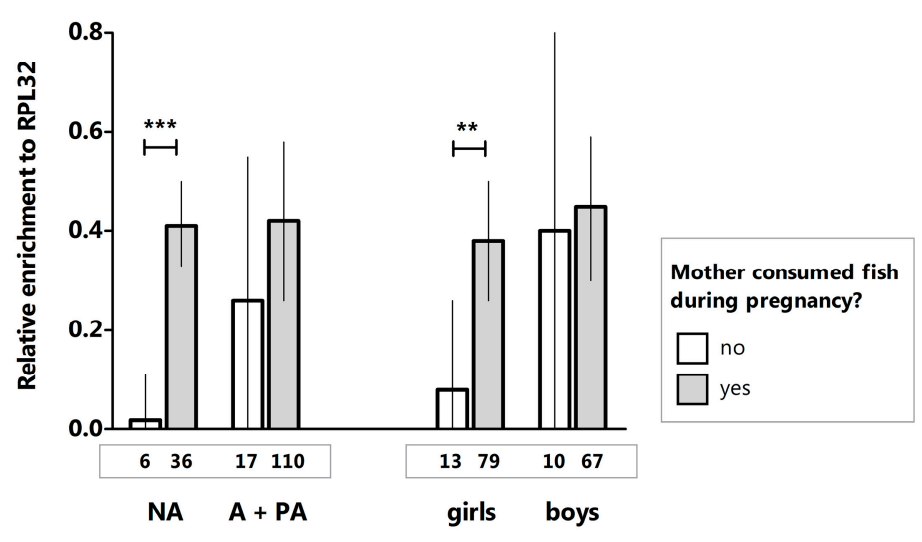

Figure 3. H4 histone acetylation levels (median with 95\% confidence interval) at the CD14 promoter in placenta according to maternal fish consumption during pregnancy. NA denotes non-anthroposophic group; A, anthroposophic group; PA, partially anthroposophic group. Numbers of mothers with complete data on dietary exposures are presented below the bars. ${ }^{* *} p<0.0001,{ }^{* *} p<0.01$.

Observations of associations in certain lifestyle groups merits further investigation but may be attributable to interactions with other factors present in these lifestyles. Indeed, specific combinations of nutritional factors may affect the outcomes of a given exposure. For instance, the beneficial effects of grape polyphenols are ameliorated by the presence of high-fat diets [29]. In this study, the maternal intake of olive oil contributed to more pronounced effects on the $\mathrm{H} 3$ acetylation levels in the placentas of anthroposophic families in comparison with non-anthroposophic families (Figure 2). Moreover, $\mathrm{H} 4$ acetylation levels at the CD14 promoter were similar in all mothers, irrespective of their lifestyle, provided that they had consumed fish during pregnancy; however, for mothers who did not consume fish, the difference in $\mathrm{H} 4$ acetylation was significant only in the group of non-anthroposophic mothers (Figure 3). We hypothesize that other exposures in the anthroposophic environment "compensated" for the lack of maternal intake of fish and led to detectable acetylation levels even if the mother did not consume fish (Figure 3). Our sample size precluded combined effects analyses, such as "olive oil + butter" or "fish + butter" on H3 and H4 acetylation levels. A vegetarian diet was also a factor that may have influenced these results but the sample size (Table 1) precluded any formal analysis. Accordingly, future interaction studies are needed to identify factors in the anthroposophic lifestyle that may be implicated in modifying histone acetylation levels.

The association detected in placentas of female offspring is in agreement with recent experimental models showing that the maternal diet exerts sex-specific effects on fetuses and placentas [18] and that sexual dimorphism does exist in the placental response to the maternal environment [30]. A high-fat 
diet during gestation triggers sex-specific epigenetic alterations in $\mathrm{CpG}$ sites (i.e. regions of DNA where a cytosine nucleotide is directly followed by a guanine nucleotide in the linear $5^{\prime} \rightarrow 3^{\prime}$ order) throughout the genome, together with the deregulation of clusters of imprinted genes [31].

Because the specimens analyzed in this study comprise the entire thickness of the placenta, the cell heterogeneity did not allow any interpretation as to which cells the $\mathrm{H} 3$ and $\mathrm{H} 4$ acetylation changes could be ascribed. In addition, the analysis of $\mathrm{H} 3$ and $\mathrm{H} 4$ pan-acetylation levels in each of the genes did not allow us to discriminate individual marks, which underlie the associations detected in this study. Therefore, the association signals detected here require additional fine-mapping with higher resolution methods to solve histone landscapes. Furthermore, elevated $\mathrm{H} 3$ and $\mathrm{H} 4$ acetylation levels are presumed to promote increased mRNA expression. However, several studies indicate that functional effects of histone acetylation affect the expression of other genomic regions but not the directly underlying gene. For example, a recent study by Kelly et al. indicated that only $10 \%$ of the genes showing differential histone acetylation demonstrated differential gene expression [32]. It is also well known that transcriptional activation at many promoters is not associated with increased histone acetylation [33]. Therefore, measuring mRNA expression in genes that show differential histone acetylation in placenta would have been very informative on the potential functional effects of the measured acetylation differences. Unfortunately, the design of our study precluded robust analyses of this type. The manner in which the $\mathrm{H} 3$ and $\mathrm{H} 4$ acetylation differences found in the placenta are reflected at the gene expression level merits further research using the data acquired from this study.

In conclusion, this study provides the first empirical evidence that maternal dietary exposure to olive oil and fish are associated with histone acetylation levels in human placenta. How these epigenetic changes contribute to immune maturation and immune development in fetal tissues merits additional study. An increased understanding of the modifying effects of olive oil intake during pregnancy on acetylation open new preventive avenues and lay the foundation for further mechanistic studies.

\section{Methods}

\subsection{Study Population-the ALADDIN Cohort}

Individuals analyzed in this study belonged to the prospective birth cohort Assessment of Lifestyle and Allergic Disease During INfancy (ALADDIN), which consists of families recruited between September 2004 and November 2007 at anthroposophic and conventional maternal health care centers in the Stockholm area, Sweden. Classification of the participating families into an anthroposophic, partly anthroposophic, or non-anthroposophic lifestyle is described in detail elsewhere [21]. Inclusion criteria for the present study were no severe illness before or during pregnancy, $\geq 36$ weeks of gestation, and availability of snap frozen placenta specimens stored at $-80^{\circ} \mathrm{C}$; these criteria resulted in 173 placentas. The study was conducted in accordance with the Declaration of Helsinki and was approved by the Regional Ethical Review Board in Stockholm (project Dnr 2010/1811-32; approval date: 15 November 2010). All parents gave their written informed consent for inclusion.

\subsection{Collection of Placenta Specimens and Histopathology Examination}

The placentas $(n=173)$ were collected by midwifes directly after birth, put on ice, and sent to the laboratory at the Karolinska University Hospital (Solna, Sweden). Because deliveries occurred at different hospitals and in diverse homes, transportation time was anticipated to vary. As such, we recorded the time from delivery until proper storage in the laboratory for each placenta. There were no significant differences in the placentas stored on ice between the non-anthroposophic group, median $23.5 \mathrm{~h}$ (range 5-73 h, $n=43$ ) and the fused anthroposophic + partly anthroposophic group, median $19.3 \mathrm{~h}$ (range $2-91 \mathrm{~h}, n=128 ; p=0.092$, Mann-Whitney $\mathrm{U}$ test). From each placenta, a cross-sectional sample about $0.5 \mathrm{~cm}$ thick, $1.5 \mathrm{~cm}$ wide, and spanning the whole thickness of the placenta was cut near the umbilical cord; each sample was quickly washed two times in phosphate-buffered saline (PBS) to remove as much blood as possible, snap frozen on dry ice, and stored at $-80^{\circ} \mathrm{C}$. 


\subsection{Isolation of Chromatin, Chromatin Immunoprecipitation, and Quantitative Polymerase Chain Reaction ( $q P C R)$}

A subsection spanning the thickness of the placenta sample was first kept for $8 \mathrm{~min}$ in $1 \mathrm{~mL} 1 \%$ paraformaldehyde (Sigma-Aldrich, Munich, Germany) at room temperature (RT). Next, the sample was centrifuged for $5 \mathrm{~min}$ at $7870 \mathrm{~g}$ at RT, incubated with $1 \mathrm{~mL} 0.25 \%$ trypsin ethylenediaminetetraacetic acid (Thermo Fisher Scientific, Waltham, MA, USA) for $1 \mathrm{~h}$ at RT, and then centrifuged again for $5 \mathrm{~min}$ at $7870 \mathrm{~g}$ at RT. The supernatant was discarded and the tissue components were incubated with $0.1 \%$ collagenase (Roche Diagnostics, Mannheim, Germany) for another hour at RT, and then centrifuged again for $5 \mathrm{~min}$ at $7870 \mathrm{~g}$ at RT. To purify cells from tissue remnants and cell debris, the pellet was then re-suspended in $1 \mathrm{~mL}$ phosphate buffered saline (PBS; Sigma-Aldrich) and run through a $0.2 \mu \mathrm{m}$ sieve. Next, the cells were washed twice with $1 \mathrm{~mL}$ PBS. Further steps, including chromatin purification, chromatin immunoprecipitation (ChIP), and quantitative assessment of both $\mathrm{H} 3$ and $\mathrm{H} 4$ histone acetylation at the gene promoters by polymerase chain reaction (PCR), were conducted as validated and described before [34] using the PCR primers presented in Table 3.

Table 3. Primers used for quantitative assessment of $\mathrm{H} 3$ or $\mathrm{H} 4$ histone acetylation.

\begin{tabular}{ccc}
\hline Gene & Forward Primer & Reverse Primer \\
\hline FOXP3 & ATCGTGAGGATGGATGCATTAATA & CCACTGGGAAGGTCCCTAGC \\
\hline$I L 10 R A$ & GCAACTACCTCCTCCCCATT & GCCTTCGGATCAAAGTGGTC \\
\hline$I L 7 R$ & AACCCCGTCTCCACTGAAAA & GAGTCTTGCTTTGTTGCCCA \\
\hline CD14 & ATCAGGGTTCACAGAGGA & GACCCCAAGACCCTACAC \\
\hline RPL32 & GGAAGTGCTTGCCTTTTTCC & GGATTGCCACGGATTAACAC \\
\hline
\end{tabular}

Three-level strategy of PCR data normalization was applied. First, percent enrichment to the input control was calculated for each target locus and a positive control gene encoding ribosomal protein L32 (RPL32), separately for mock (IgG), and H3 and H4 antibodies. Then, locus-specific percent enrichment to the input control obtained for IgG was subtracted from the corresponding values for H3 or H4 antibodies. Such calculated IgG-corrected percent enrichment was divided for each gene into that of RPL32, resulting in a relative enrichment value, which was used for subsequent statistical analyses [34,35]. Intra- and interassay coefficients of variation calculated for percent enrichment should not exceed 10\% [34]. All samples were processed according to the same standardized protocol, analyzed blinded, and in a randomized order.

\subsection{Statistics}

A comparison of demographic and exposure variables between the study groups were performed by $\chi^{2}$ and the Mann-Whitney U test. Given the distribution of the acetylation data, the relationship between exposure factors on histone acetylation levels were first calculated using the Mann-Whitney U test. Subsequently, more detailed analyses, including those with adjustments, were performed by median regression, which generally outperforms standard linear regression in the presence of outliers or asymmetric, possibly heavy-tailed distributions. Regression coefficients with 95\% confidence intervals (CIs) were reported. With binary predictors, the regression coefficient represents a difference between medians; with continuous predictors, it is interpreted as the change in the median outcome associated with a unit increase in the predictor. To fit quantile regression models and compute standard errors, we used conventional bootstrap techniques, as implemented by the $\mathrm{R}$ package quantreg, version 5.29 (https:/ / cran.rproject.org/web/packages/quantreg/). A value of $p<0.05$ was considered statistically significant. 
Author Contributions: Conceptualization: A.S., H.R.; Methodology: H.H., H.R.; Software: P.F., N.A.; Validation: H.H., J.A.; Formal Analysis: P.F., N.A., D.P.P.; Investigation: H.H., B.A.A., L.E., C.J., J.A., A.S.; Resources: A.S., J.A., C.J., H.R.; Data Curation: P.F.; Writing-Original Draft Preparation: N.A., P.F., A.S., D.P.P.; Writing-Review \& Editing: All authors; Visualization: N.A., P.F.; Supervision: A.S., H.R., D.P.P.; Project Administration: A.S., J.A., H.R., D.P.P.; Funding Acquisition: A.S., J.A., N.A., H.R., D.P.P., H.H., B.A.A.

Funding: This study was supported by the Swedish Research Council (2012-3011), the German Center for Lung Research (DZL; 82DZL00502/A2), the Swedish Research Council for Working Life and Social Research (2006-1630), the regional agreement on medical training and clinical research (ALF) between Stockholm County Council and the Karolinska Institutet and the Karolinska University Hospital, the King Gustaf V:s 80-årsfond (FAA-2015-0151), the Swedish Society of Medicine, the Centre for Allergy Research Karolinska Institutet, the Mjölkdroppen Society, the Swedish Asthma and Allergy Research Association, the Cancer and Allergy Fund, the Ekhaga Foundation, the Frimurare Barnhuset Foundation in Stockholm, the Hesselman Foundation, the Samariten Foundation, the Varrdal Foundation, the Universities Giessen and Marburg Lung Centre (UGMLC), the Von Behring-Röntgen-Foundation (Von Behring-Röntgen-Stiftung; 62-LV04), and the German Academic Exchange Service (DAAD; B Alashkar Alhamwe, personal reference number: 91559386).

Acknowledgments: We acknowledge the families participating in the ALADDIN study for their trust and contribution and the ALADDIN team for their involvement in this work, especially Margareta Eriksson, Fredrik Stenius, and Monica Nordlund and Carina Wallén. We thank Matteo Bottai, Karolinska Institutet, for statistical advice.

Conflicts of Interest: J.A. has served as a consultant on clinical trials for ALK-Abello. A.S. is a member in the Joint Steering Committee for the Human Translational Microbiome Program at SciLifeLab/Karolinska Institutet together with Ferring Pharmaceuticals, Switzerland. The rest of the authors declare that they have no relevant conflicts of interest.

\section{References}

1. Lecoutre, S.; Pourpe, C.; Butruille, L.; Marousez, L.; Laborie, C.; Guinez, C.; Lesage, J.; Vieau, D.; Eeckhoute, J.; Gabory, A.; et al. Reduced PPARgamma2 expression in adipose tissue of male rat offspring from obese dams is associated with epigenetic modifications. FASEB J. 2018, 32, 2768-2778. [CrossRef] [PubMed]

2. Block, T.; El-Osta, A. Epigenetic programming, early life nutrition and the risk of metabolic disease. Atherosclerosis 2017, 266, 31-40. [CrossRef] [PubMed]

3. Lee, H.S. Impact of Maternal Diet on the Epigenome during In Utero Life and the Developmental Programming of Diseases in Childhood and Adulthood. Nutrients 2015, 7, 9492-9507. [CrossRef] [PubMed]

4. Chen, J.R.; Lazarenko, O.P.; Zhao, H.; Alund, A.W.; Shankar, K. Maternal obesity impairs skeletal development in adult offspring. J. Endocrinol. 2018. [CrossRef] [PubMed]

5. Isaac, A.R.; da Silva, E.A.N.; de Matos, R.J.B.; Augusto, R.L.; Moreno, G.M.M.; Mendonça, I.P.; de Souza, R.F.; Cabral-Filho, P.E.; Rodrigues, C.G.; Gonçalves-Pimentel, C.; et al. Low omega-6/omega-3 ratio in a maternal protein-deficient diet promotes histone-3 changes in progeny neural cells and favors leukemia inhibitory factor genetranscription. J. Nutr. Biochem. 2018, 55, 229-242. [CrossRef] [PubMed]

6. Upadhyaya, B.; Larsen, T.; Barwari, S.; Louwagie, E.J.; Baack, M.L.; Dey, M. Prenatal Exposure to a Maternal High-Fat Diet Affects Histone Modification of Cardiometabolic Genes in Newborn Rats. Nutrients 2017, 9, 407. [CrossRef] [PubMed]

7. Voss, A.K.; Thomas, T. Histone Lysine and Genomic Targets of Histone Acetyltransferases in Mammals. BioEssays 2018, 40, e1800078. [CrossRef] [PubMed]

8. Brook, P.O.; Perry, M.M.; Adcock, I.M.; Durham, A.L. Epigenome-modifying tools in asthma. Epigenomics 2015, 7, 1017-1032. [CrossRef] [PubMed]

9. Vahid, F.; Zand, H.; Nosrat-Mirshekarlou, E.; Najafi, R.; Hekmatdoost, A. The role dietary of bioactive compounds on the regulation of histone acetylases and deacetylases: A review. Gene 2015, 562, 8-15. [CrossRef] [PubMed]

10. Triff, K.; McLean, M.W.; Callaway, E.; Goldsby, J.; Ivanov, I.; Chapkin, R.S. Dietary fat and fiber interact to uniquely modify global histone post-translational epigenetic programming in a rat colon cancer progression model. Int. J. Cancer 2018, 143, 1402-1415. [CrossRef] [PubMed]

11. Harb, H.; Irvine, J.; Amarasekera, M.; Hii, C.S.; Kesper, D.A.; Ma, Y.F.; D’Vaz, N.; Renz, H.; Potaczek, D.P.; Prescott, S.L.; et al. The role of PKCzeta in cord blood T-cell maturation towards Th1 cytokine profile and its epigenetic regulation by fish oil. Biosci. Rep. 2017, 37, BSR20160485. [CrossRef] [PubMed] 
12. Alaskhar Alhamwe, B.; Khalaila, R.; Wolf, J.; von Bulow, V.; Harb, H.; Alhamdan, F.; Hii, C.S.; Prescott, S.L.; Ferrante, A.; Renz, H.; et al. Histone modifications and their role in epigenetics of atopy and allergic diseases. Allergy Asthma Clin. Immunol. 2018, 14, 39. [CrossRef] [PubMed]

13. Kang, S.G.; Lim, H.W.; Andrisani, O.M.; Broxmeyer, H.E.; Kim, C.H. Vitamin A metabolites induce gut-homing FoxP3+ regulatory T cells. J. Immunol. 2007, 179, 3724-3733. [CrossRef] [PubMed]

14. Furusawa, Y.; Obata, Y.; Fukuda, S.; Endo, T.A.; Nakato, G.; Takahashi, D.; Nakanishi, Y.; Uetake, C.; Kato, K.; Kato, T.; et al. Commensal microbe-derived butyrate induces the differentiation of colonic regulatory $\mathrm{T}$ cells. Nature 2013, 504, 446-450. [CrossRef] [PubMed]

15. Arpaia, N.; Campbell, C.; Fan, X.; Dikiy, S.; van der Veeken, J.; de Roos, P.; Liu, H.; Cross, J.R.; Pfeffer, K.; Coffer, P.J.; et al. Metabolites produced by commensal bacteria promote peripheral regulatory T-cell generation. Nature 2013, 504, 451-455. [CrossRef] [PubMed]

16. Thorburn, A.N.; McKenzie, C.I.; Shen, S.; Stanley, D.; Macia, L.; Mason, L.J.; Roberts, L.K.; Wong, C.H.Y.; Shim, R.; et al. Evidence that asthma is a developmental origin disease influenced by maternal diet and bacterial metabolites. Nat. Commun. 2015, 6, 7320. [CrossRef] [PubMed]

17. Nugent, B.M.; Bale, T.L. The omniscient placenta: Metabolic and epigenetic regulation of fetal programming. Front. Neuroendocrinol. 2015, 39, 28-37. [CrossRef] [PubMed]

18. Panchenko, P.E.; Voisin, S.; Jouin, M.; Jouneau, L.; Prezelin, A.; Lecoutre, S.; Breton, C.; Jammes, H.; Junien, C.; Gabory, A. Expression of epigenetic machinery genes is sensitive to maternal obesity and weight loss in relation to fetal growth in mice. Clin. Epigenet. 2016, 8, 22. [CrossRef] [PubMed]

19. Ramaiyan, B.; Talahalli, R.R. Dietary Unsaturated Fatty Acids Modulate Maternal Dyslipidemia-Induced DNA Methylation and Histone Acetylation in Placenta and Fetal Liver in Rats. Lipids 2018, 53, 581-588. [CrossRef] [PubMed]

20. Slaats, G.G.; Reinius, L.E.; Alm, J.; Kere, J.; Scheynius, A.; Joerink, M. DNA methylation levels within the CD14 promoter region are lower in placentas of mothers living on a farm. Allergy 2012, 67, 895-903. [CrossRef] [PubMed]

21. Stenius, F.; Swartz, J.; Lilja, G.; Borres, M.; Bottai, M.; Pershagen, G.; Scheynius, A.; Alm, J. Lifestyle factors and sensitization in children - the ALADDIN birth cohort. Allergy 2011, 66, 1330-1338. [CrossRef] [PubMed]

22. Hinz, D.; Bauer, M.; Roder, S.; Olek, S.; Huehn, J.; Sack, U.; Borte, M.; Simon, J.C.; Lehmann, I.; Herberth, G. Cord blood Tregs with stable FOXP3 expression are influenced by prenatal environment and associated with atopic dermatitis at the age of one year. Allergy 2012, 67, 380-389. [CrossRef] [PubMed]

23. Luccarini, I.; Grossi, C.; Rigacci, S.; Coppi, E.; Pugliese, A.M.; Pantano, D.; la Marca, G.; Ed Dami, T.; Berti, A.; Stefani, M.; et al. Oleuropein aglycone protects against pyroglutamylated-3 amyloid-ss toxicity: Biochemical, epigenetic and functional correlates. Neurobiol. Aging 2015, 36, 648-663. [CrossRef] [PubMed]

24. Bonvino, N.P.; Ray, N.B.; Luu, V.T.; Liang, J.; Hung, A.; Karagiannis, T.C. Exploration of mechanisms in nutriepigenomics: Identification of chromatin-modifying compounds from Olea Europaea. Hell. J. Nucl. Med. 2015, 18, 51-62. [PubMed]

25. Serra, G.; Incani, A.; Serreli, G.; Porru, L.; Melis, M.P.; Tuberoso, C.I.G.; Rossin, D.; Biasi, F.; Deiana, M. Olive oil polyphenols reduce oxysterols -induced redox imbalance and pro-inflammatory response in intestinal cells. Redox Biol. 2018, 17, 348-354. [CrossRef] [PubMed]

26. Lucas, L.; Russell, A.; Keast, R. Molecular mechanisms of inflammation. Anti-inflammatory benefits of virgin olive oil and the phenolic compound oleocanthal. Curr. Pharm. Des. 2011, 17, 754-768. [CrossRef] [PubMed]

27. Rigacci, S.; Stefani, M. Nutraceutical Properties of Olive Oil Polyphenols. An Itinerary from Cultured Cells through Animal Models to Humans. Int. J. Mol. Sci. 2016, 17, 843. [CrossRef] [PubMed]

28. Burdge, G.C.; Lillycrop, K.A. Fatty acids and epigenetics. Curr. Opin. Clin. Nutr. Metab. Care 2014, 17, 156-161. [CrossRef] [PubMed]

29. Goncalves, L.K.; da Silva, I.R.V.; Cechinel, L.R.; Frusciante, M.R.; de Mello, A.S.; Elsner, V.R.; Funchal, C.; Dani, C. Maternal consumption of high-fat diet and grape juice modulates global histone $\mathrm{H} 4$ acetylation levels in offspring hippocampus: A preliminary study. Neurosci. Lett. 2017, 661, 29-32. [CrossRef] [PubMed]

30. Tarrade, A.; Panchenko, P.; Junien, C.; Gabory, A. Placental contribution to nutritional programming of health and diseases: Epigenetics and sexual dimorphism. J. Exp. Biol. 2015, 218, 50-58. [CrossRef] [PubMed]

31. Gabory, A.; Ferry, L.; Fajardy, I.; Jouneau, L.; Gothie, J.D.; Vigé, A.; Fleur, C.; Mayeur, S.; Gallou-Kabani, C.; Gross, M.S.; et al. Maternal diets trigger sex-specific divergent trajectories of gene expression and epigenetic systems in mouse placenta. PLoS ONE 2012, 7, e47986. [CrossRef] [PubMed] 
32. Kelly, D.; Kotliar, M.; Woo, V.; Jagannathan, S.; Whitt, J.; Moncivaiz, J.; Aronow, B.J.; Dubinsky, M.C.; Hyams, J.S.; Markowitz, J.F.; et al. Microbiota-sensitive epigenetic signature predicts inflammation in Crohn's disease. JCI Insight 2018, 3, e122104. [CrossRef] [PubMed]

33. Deckert, J.; Struhl, K. Histone acetylation at promoters is differentially affected by specific activators and repressors. Mol. Cell. Biol. 2001, 21, 2726-2735. [CrossRef] [PubMed]

34. Harb, H.; Amarasekera, M.; Ashley, S.; Tulic, M.K.; Pfefferle, P.I.; Potaczek, D.P.; Martino, D.; Kesper, D.A.; Prescott, S.L.; Renz, H. Epigenetic Regulation in Early Childhood: A Miniaturized and Validated Method to Assess Histone Acetylation. Int. Arch. Allergy Immunol. 2015, 168, 173-181. [CrossRef] [PubMed]

35. Haring, M.; Offermann, S.; Danker, T.; Horst, I.; Peterhansel, C.; Stam, M. Chromatin immunoprecipitation: Optimization, quantitative analysis and data normalization. Plant Methods 2007, 3, 11. [CrossRef] [PubMed]

(c) 2019 by the authors. Licensee MDPI, Basel, Switzerland. This article is an open access article distributed under the terms and conditions of the Creative Commons Attribution (CC BY) license (http:/ / creativecommons.org/licenses/by/4.0/). 